\title{
Uso de dados de avaliação para escolha de escolas para um Survey: desafios para a imaginação e o rigor metodológico
}

Cynthia Paes de Carvalho*

Luiza Helena Lamego Felipe**

Diana Mandelert ${ }^{* * *}$

\section{Resumo}

0 texto descreve e discute o processo de seleção das escolas para uma pesquisa em que foram utilizados resultados de avaliações externas do sistema educacional brasileiro dos anos 2005, 2006 e 2007. Pretendeu-se dessa forma aprofundar o estudo dos mecanismos e práticas institucionais que produzem o sucesso escolar, decidimos realizar um survey em oito escolas, quatro públicas municipais e quatro privadas. A pesquisa focaliza as práticas pedagógicas e os processos de gestão em estabelecimentos escolares do município do Rio de Janeiro que são reconhecidos pela excelência do ensino ministrado a partir dos resultados alcançados por seus alunos em exames públicos que avaliam o desempenho escolar. Para isso, analisamos os resultados das diferentes escolas, tornando o próprio processo de seleção como uma etapa da pesquisa. Pretende-se assim articular informações macro e micro com vistas à viabilização de uma análise relacional dos dados que serão coletados e contribuir para a discussão metodológica no campo da sociologia da educação.

Palavras-chave: Escolas. Metodologia de pesquisa. Sucesso escolar.

\section{The use of evaluation data to select schools for a Survey: challenges to the imagination and methodological rigorousness Abstract}

The text describes and discusses the selection process of schools for a research, which used the results of the external evaluations of the

* Doutora em Ciências Humanas, Profa. e Pesquisadora, Departamento de Educação, Pontifícia Universidade Católica do Rio de Janeiro (PUC-Rio). E-mail: cynthiapaesdecarvalho@puc-rio.br

** Mestre em Educação, PUC- Rio; Doutoranda em Educação, PUC-Rio; Profaq1 do Colégio Pedro II. Email:luizahfelipe@gmail.com

*** Mestre em Educação, PUC- Rio; Doutoranda em Educação PUC-Rio. E-mail:mandelert@oi.com.br

Ensaio: aval. pol. públ. Educ., Rio de Janeiro, v. 19, n. 70, p. 127-148, jan./mar. 2011 
Brazilian school system from 2005, 2006 and 2007. Aiming to deepen the study of the organizations and institutional practices that produce schooling success, we decided to develop a survey at eight schools: four public administrated by the municipality, and four private ones. The research focuses the pedagogical practices and management processes at those schools of the municipality of Rio de Janeiro that are recognized through the excellence of their teaching, considering the results their students achieve in public exams that evaluate their performance. Therefore, we analyzed the results of the various schools, turning the selection process itself a stage of the research. Thereby, we intend to articulate macro and micro information in order to make feasible a relational analysis of the data that shall be collected and contribute to the methodological discussion in the field of sociology of education. Keywords: Schools. Research methodology. School success.

\section{Uso de datos de evaluación para selección de escuelas para un survey - desafios para la imaginación $y$ el rigor metodológico Resumen}

El texto describe y discute el proceso de selección de escuelas con el fin de obtener una investigación y en la que se utilizaron los resultados de evaluaciones externas del sistema educacional brasileño de los años 2005, 2006 y 2007. Se buscó profundizar el estudio de los mecanismos y las prácticas institucionales que producen el éxito escolar, se realizó un survey (encuesta) en ocho escuelas, cuatro públicas municipales y cuatro privadas. La investigación focalizó las practicas pedagógicas y los procesos de gestión en establecimientos escolares de la municipalidad de Río de Janeiro reconocidos por la excelencia de su enseñanza a partir de resultados alcanzados por sus alumnos en exámenes públicos que evalúan el desempeño escolar. Para eso analizamos los resultados de las diferentes escuelas, tornando el propio proceso de selección una etapa de la investigación. La perspectiva es articular informaciones tanto macro como micro de modo tal a que se pueda viabilizar un análisis relacional de los datos que serán recolectados y poder contribuir, así, para la discusión metodológica en el campo de la sociología de la educación.

Palabras clave: Escuelas. Metodología de investigación. Éxito escolar.

\section{Introdução}

De 2001 a 2007, o Grupo de Pesquisas em Sociologia da Educação (SOCED) da PUC-Rio - criado e coordenado pela Profa. Zaia Brandão, desenvolveu um progra- 
ma de pesquisas em escolas ${ }^{1}$ privadas e públicas (federais) que favorecem o bom desempenho dos alunos com base num survey com pais, alunos e professores, complementado por um extenso conjunto de observações e entrevistas de campo. 0 critério de seleção das escolas neste primeiro survey foi o definido por Levin (1987, p. 120) como não-casual de julgamento ou conveniência, de acordo como qual "a lógica, o senso comum ou um julgamento equilibrado podem ser usados na seleção de uma amostra que seja representativa de um grupo maior (população)"2. Assim, foram selecionadas escolas que anualmente conquistavam as melhores posições nos rankings dos vestibulares das principais universidades do Rio de Janeiro, considerando também diferentes tipos de projeto pedagógico, supondo encontrar assim também alguma variedade em termos de caracterização sóciodemográfica e cultural da clientela (pais e alunos). Este momento da escolarização em contextos institucionais que abrangem todas as séries do ensino fundamental foi privilegiado para a investigação, por consideramos que nele a experiência escolar já se encontra consolidada, e os jovens apresentam características tanto do ensino fundamental, quanto do ensino médio (MANDELERT, 2005).

Alternando análises de dados coletados através de survey junto a pais, professores e alunos, com estudos de caso que privilegiaram uma perspectiva interacionista, desenvolvemos uma compreensão das singularidades institucionais e sua influência nos processos de construção da qualidade do ensino. No biênio 2009/2010, optamos por ampliar o universo investigado na cidade do Rio de Janeiro e abranger também escolas públicas municipais de qualidade. Buscamos, assim, aprofundar a análise na perspectiva relacional proposta por Bourdieu, estudando diferentes projetos institucionais e aspectos da gestão escolar, particularmente aqueles relacionados ao desenvolvimento do habitus escolar dos alunos, considerando para tanto as práticas de gestão pedagógica e a relação de cada escola com as famílias de seus alunos.

A maior focalização do estudo ora pretendida, a inclusão das escolas municipais no universo da pesquisa e o aprofundamento do estudo em escolas privadas ainda não investigadas, reforçaram a necessidade de aprimorar o processo de seleção das escolas para participar da nova etapa de investigação. A preocupação se justificou em razão dos aprendizados já auferidos pelos membros do grupo no campo de investigação, que poderiam favorecer vieses na escolha das novas escolas, reforçando a necessidade de estabelecer procedimentos bem delineados que assegurassem o

1 Todas as escolas ofereciam todas as séries da Educação Básica, ou seja, tinham ensino fundamental completo e também ensino médio, o que implicava a possibilidade de conhecer os resultados de seus alunos nos exames de admissão das universidades, critério considerado para sua identificação como estabelecimentos que favorecem o bom desempenho (BRANDÃO; MANDERLET; DE PAULA, 2005).

2 Para explicar este tipo de amostra, Levin (1987, p. 120) dá o seguinte exemplo: "para extrair uma amostra de revistas que reflitam valores da classe média norte-americana, poderíamos levados apenas pela intuição, selecionar Reader's Digest, People ou Parade, uma vez que os artigos dessas revistas parecem refletir aquilo que a maioria dos norte-americanos de classe média deseja (por exemplo, a satisfação do sonho americano, sucesso econômico e coisas semelhantes)”. 
controle rigoroso e isento da nova seleção (MARTINS, 2004). Buscou-se dessa forma aliar o rigor metodológico sem perder de vista o interesse em manter a vantagem heuristica de estudar escolas de redes educacionais diferentes (públicas e privadas), na perspectiva do desenvolvimento de uma análise relacional como propõe Pierre Bourdieu (1997). A escolha pretendeu viabilizar o estudo de diferentes contextos institucionais, considerando, de um lado, o sucesso escolar dos alunos avalizado também por medidas externas de proficiência, e de outro, a questão de seu background socioeconômico e cultural, conforme a tradição já consolidada da pesquisa em sociologia da educação.

Para a atual etapa de aprofundamento da pesquisa, optou-se por privilegiar os resultados acadêmicos que lastreiam o prestígio dos estabelecimentos aferidos no processo de escolha das escolas tanto na rede privada, quanto na pública. No caso da rede privada de ensino utilizamos os resultados no Exame Nacional do Ensino Médio- ENEM, por este ser o único exame que contempla as escolas privadas sem ter a forma amostral do Sistema de Avaliação da Educação Básica (SAEB), além de ser uma avaliação mais próxima da $8^{\text {a }}$ série $/ 9^{\circ}$ ano do ensino fundamental, período privilegiado no estudo, conforme já assinalado. No caso da rede pública municipal, foram usados os resultados das escolas na Prova Brasil 2005 e 2007, tanto na $4^{\text {a }}$ como na $8^{a}$ Série do ensino fundamental.

Além disso, os critérios de seleção consideraram também o número de alunos matriculados em cada escola de forma a integrar no processo de seleção também aspectos da estrutura organizacional dado o peso destes na composição do ambiente ou clima escolar (MAFRA, 2003). Buscamos, assim, estabelecimentos escolares de médio e grande porte, com mais de 800 alunos matriculados, situação da maioria das escolas privadas de prestígio já estudadas. Quando possível ${ }^{3}$, foram também considerados fatores extraescolares com base no nível socioeconômico médio dos alunos (NSE).

Foram, assim, escolhidas escolas com ensino fundamental completo com um número total de matrículas superior a 800 e com um mínimo de três turmas no $9^{\circ}$ Ano/8a série, que se caracterizam como estabelecimentos de médio e grande porte. A perspectiva é que dessa forma o estudo dos fatores intra-escolares que influenciam o desempenho dos alunos poderá ser realizado com maior acuidade, articulando informações macro e micro e viabilizando uma análise relacional dos dados coletados. 0 texto que se segue apresenta inicialmente o caminho percorrido para escolher as escolas privadas e, em seguida, o processo de seleção das escolas públicas municipais para o novo survey ${ }^{4}$, discutindo os desafios que se apresentaram e as soluções encontradas para superá-los.

3 Apenas no caso da rede municipal este controle foi viabilizado a partir da Prova Brasil e do Censo Escolar 2005.

4 Atualmente já foram aplicados questionários em todas as escolas selecionadas e as respostas (cerca de 4000 questionários) estão sendo analisadas. 


\section{Escolas públicas e privadas da cidade do Rio de Janeiro no ENEM 2005, 2006 e 2007: os limites do "mapa"}

Inicialmente, procuramos construir um "mapa" dos resultados do ENEM na cidade do Rio de Janeiro em 2005, 2006 e 2007. Estes anos foram escolhidos tanto como forma de manter o recorte de medida de desempenho num período semeIhante ao utilizado no universo da rede pública municipal ${ }^{5}$, como pelo fato de que antes deles os resultados do ENEM não eram divulgados por escola.

Em 2007, o ENEM teve 3.584.568 inscritos e 2.738 .610 participantes, localizados em cerca de 1.300 municípios espalhados por todo o país, consolidando um crescimento de $2.170 \%$ desde que a prova começou a ser aplicada em 1998, até 2007 (FERNANDES, 2008). Um dos fatores que tem contribuído para o aumento de participantes é a utilização do ENEM como um dos critérios de seleção para entrada no Ensino Superior, principalmente para aqueles que concorrem às bolsas do Programa Universidade para Todos (PROUNI) do Governo Federal.

0 perfil dos participantes é variado em termos de trajetória escolar: em 2007 apenas $33 \%$, eram concluintes do ensino médio, sendo que quase 13\% declararam que iriam concluir esse nível de ensino após 2007, e 14\% que já haviam concluído antes de 2000. Em 2006, 36\% eram concluintes do ensino médio, e, em 2005, os concluintes eram $40 \%$. Tais constatações mostram a considerável limitação dos dados disponiveis sobre as escolas privadas, uma vez que neles não está incluída a totalidade dos alunos.

Outro limite encontrado foi a identificação do percentual de escolas privadas (em relação a universo da rede na cidade) com alunos participantes do ENEM. Enquanto de acordo com os dados divulgados pelo Ministério da Educação (MEC), através do Instituto Nacional de Estudos e Pesquisas Educacionais Anisio Teixeira (INEP), havia 377 escolas privadas com ensino fundamental no município do Rio de Janeiro em 2006, em 2007 foi divulgado o resultado do ENEM de apenas 234 escolas privadas. Se o número de escolas se manteve constante, a participação seria de uma ordem de 60\%. Entretanto, como o INEP não divulgou os resultados das escolas que tinham menos de dez alunos participantes e tampouco os resultados das escolas que optaram por não declarar os dados de seus alunos no censo escolar, não foi possivel precisar melhor este percentual de participação. Talvez por esta razão algumas das escolas usualmente reconhecidas e identificadas na mídia como de prestígio tenham ficado ausentes do ranking do ENEM em 2007 (INEP, 2008b).

Em 2007, o ENEM teve 68.893 participantes na cidade do Rio de Janeiro. 0 Gráfico 1, a seguir, apresenta a evolução dos participantes e inscritos no ENEM na cidade do Rio de Janeiro em 2005, 2006 e 2007.

5 Sobre a rede municipal só era possível obter dados por escola a partir de 2005, com a implantação da Prova Brasil. 


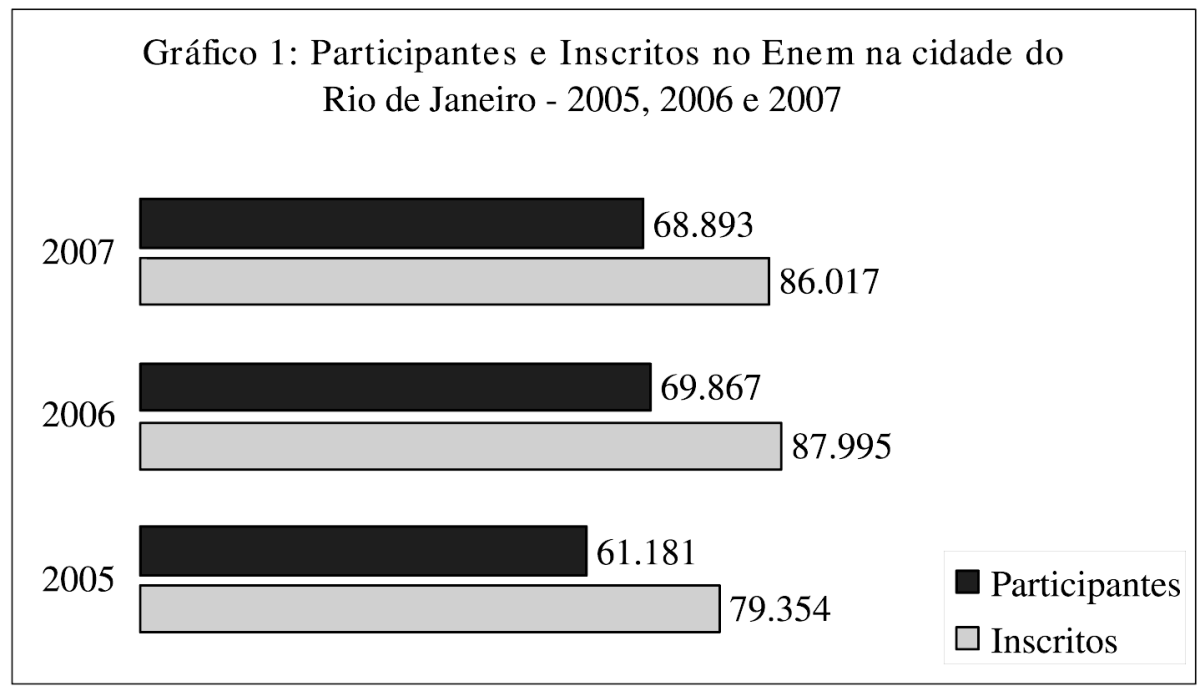

Gráfico 1: Participantes e inscritos no ENEM na cidade do Rio de Janeiro: 2005, 2006 e 2007.

Fonte: INEP (2007, 2008a, 2008b).

Como aconteceu, em termos gerais, no pais, houve uma pequena redução do número de inscritos e de participantes, em 2007. As informações fornecidas pelo INEP (2008b) não permitiam discriminar os que são concluintes do ensino fundamental de 2007, ou de anos anteriores, ou ainda aqueles que ainda estavam no $1^{\circ}$ ou no $2^{\circ}$ ano do ensino fundamental e queriam apenas testar seus conhecimentos. Como, no momento em que fizemos a seleção das escolas, os microdados do Censo Escolar 2007 ainda não estavam disponibilizados a não ser agregados por Unidade da Federação, também não foi possivel conhecer o número total de concluintes do ensino fundamental da cidade do Rio de Janeiro, embora considerando o número de alunos que participaram do ENEM por escola, em 2007, tenhamos identificado 27.156 participantes do ENEM na cidade.

A seguir os Gráficos 2 e 3 apresentam o percentual de escolas e de alunos participantes do ENEM de 2007 por rede de ensino, respectivamente. 
Gráfico 2: Escolas participantes do ENEM 2007 por rede município do Rio de Janeiro

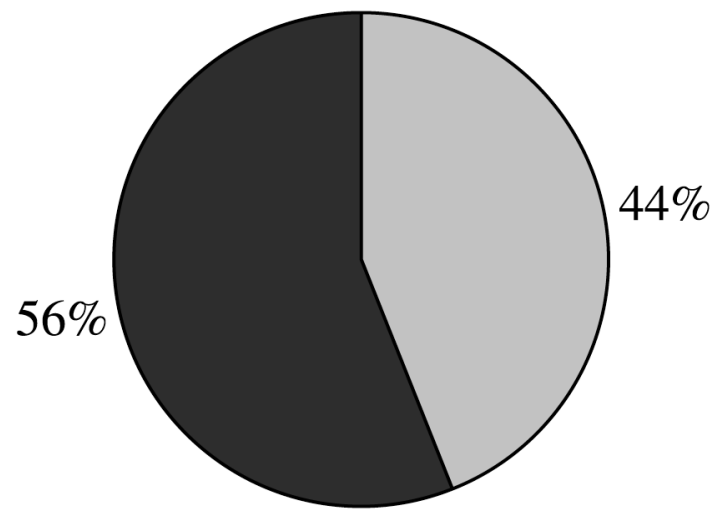

Rede Privada

Rede Pública

Gráfico 2: Escolas participantes do ENEM 2007 por rede: municipio do Rio de Janeiro. Fonte: INEP (2008b).

Gráfico 3: Alunos participantes do ENEM 2007 por tipo de escola - município do Rio de Janeiro

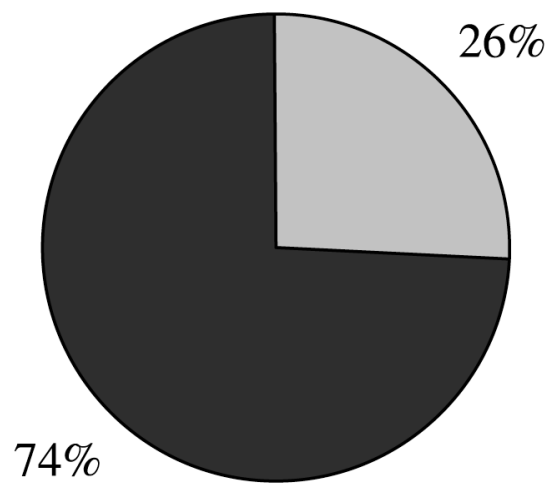

$\square$ Rede Privada

$\square$ Rede Pública

Gráfico 3: Alunos participantes do ENEM 2007 por tipo de escola: município do Rio de Janeiro.

Fonte: INEP (2008b). 
Em 2007 o número de escolas públicas participantes foi 12\% maior do que as privadase o percentual de alunos participantes da rede pública foi quase três vezes o da rede privada. Entretanto, comparando a relação entre o número de matrículas nas escolas e os participantes do ENEM, observamos que 52\% dos alunos da rede privada realizaram o exame, enquanto na rede pública foram apenas $26 \%$. Se no caso da rede privada isso talvez possa ser explicado em razão do maior atrativo do ENEM como possibilidade de uso da nota obtida para o ingresso em diversas instituições de ensino superior, muitas das quais dispõem de grande prestígio acadêmico e social, na rede pública os dados parecem apontar em outra direção. Caberia levantar a hipótese de até que ponto o horizonte dos possiveis (BOURDIEU, 1997) para a grande maioria dos alunos da rede pública de ensino inclui o ingresso na universidade, uma vez que não se inscrevem no exame, mesmo na vigência do PROUNI, que favorece a continuidade dos estudos no nível superior como uma perspectiva ao seu alcance.

Em relação às médias do ENEM, optamos por comparar a média total (redação e prova objetiva) com correção de participação no ENEM 2007, no que se refere ao Brasil, ao estado e à cidade do Rio de Janeiro, tanto em termos gerais, como para as escolas públicas e privadas separadamente, como apresentamos na tabela a seguir.

Tabela 1: Média total (redação e prova objetiva) com correção de participação no ENEM 2007.

\begin{tabular}{l|c|c|c}
\hline & Geral & Escolas Públicas & Escolas Privadas \\
\hline Brasil & 51,3 & $48,1 \%$ & $63,0 \%$ \\
\hline Estado do Rio de Janeiro & 52,8 & $48,5 \%$ & $64,1 \%$ \\
\hline Cidade do Rio de Janeiro & 54,8 & $47,8 \%$ & $66,2 \%$ \\
\hline
\end{tabular}

Fonte: /INEP (2008b).

Em termos gerais, as médias da cidade do Rio de Janeiro foram maiores que do Brasil e do estado, entretanto, analisando separadamente as escolas, esse resultado só se confirmou para as privadas, pois as públicas tiveram um resultado inferior.

\section{A escolha das escolas privadas: procedimentos e opções finais de seleção}

Embora fosse possivel considerar diretamente o ranking oferecido pelas notas do ENEM para identificar as escolas com melhor desempenho, decidimos trilhar um caminho mais lento, que nos pareceu mais seguro do ponto de vista do rigor metodológico. Por esta razão, realizamos, criteriosamente recortes sucessivos do universo potencial para a escolha - a fim de assegurar a seleção dentro de um panorama mais acurado da participação das diferentes escolas no exame. 0 procedimento adotado foi realizar recortes sucessivos no universo para delimitar subconjuntos de escolas consistentes com o foco principal da pesquisa pretendida. 
Como primeiro recorte, retiramos da listagem das escolas participantes do ENEM aquelas que só ofereciam Educação de Jovens e Adultos (EJA), uma vez que pretendemos estudar apenas escolas que oferecem ensino regular. A Tabela 2 a seguir mostra o número de escolas que tinham apenas EJA na cidade do Rio de Janeiro ${ }^{6}$ e 0 número de alunos participantes do ENEM destas escolas, por rede de ensino, que representavam $6,4 \%$ do total de escolas participantes, embora seus alunos correspondessem a apenas $2,8 \%$ do total de alunos que participaram do ENEM naquele ano.

Tabela 2: Escolas participantes do ENEM na cidade do Rio de Janeiro que ofereciam apenas EJA.

\begin{tabular}{l|c|c}
\hline Escolas & N & Alunos participantes \\
\hline Privadas & 16 & 149 \\
\hline Públicas & 18 & 626 \\
\hline Total & 34 & 755 \\
\hline
\end{tabular}

Fonte: INEP (2008b).

Posteriormente, verificamos o número de escolas sem conceito ${ }^{7}$ e seus participantes para avaliar sua representatividade no universo do ENEM 2007. A Tabela 3 a seguir mostra que as escolas privadas e públicas sem conceito representaram 12,5\% do total de escolas participantes, e seus alunos corresponderam a apenas 1,4\% do total de participantes. Concluimos então que as escolas sem conceito formavam na verdade um grupo residual.

Tabela 3: Escolas sem conceito que participaram do ENEM 2007 na cidade do Rio de Janeiro.

\begin{tabular}{l|c|c}
\hline Escolas & N & Alunos participantes \\
\hline Privadas & 53 & 287 \\
\hline Públicas & 14 & 87 \\
\hline Total & 67 & 374 \\
\hline
\end{tabular}

Fonte: INEP (2008b).

Optamos, então, por não manter no universo de escolha as escolas apenas com EJA e as escolas sem conceito, chegando assim ao universo de escolas, descrito na Tabela 4 a seguir, a partir do qual selecionamos as escolas para a pesquisa.

6 Dentre aquelas cujos alunos se inscreveram no ENEM em 2007.

7 Escolas com menos de 10 alunos concluintes, participantes do ENEM em 2007 ou menos de 10 alunos matriculados na escola. 
Tabela 4: Escolas participantes do ENEM 2007 na cidade do Rio de Janeiro com conceito e sem EJA.

\begin{tabular}{l|c|c|c|c}
\hline \multirow{2}{*}{ Escolas } & \multicolumn{2}{|c|}{$\mathrm{N}$} & \multicolumn{2}{c}{ Alunos participantes } \\
\cline { 2 - 5 } & $\mathrm{N}^{\circ}$ & Percentual & $\mathrm{N}^{\circ}$ & Percentual \\
\hline Privadas & 165 & $38 \%$ & 6.556 & $25 \%$ \\
\hline Públicas & 268 & $62 \%$ & 19.451 & $75 \%$ \\
\hline Total & 433 & $100 \%$ & 26.007 & $100 \%$ \\
\hline
\end{tabular}

Fonte: INEP (2008b).

Cabe observar que, mesmo nesse subconjunto das escolas participantes do ENEM 2007 no município do Rio de Janeiro, o número de alunos da rede pública continuava a ser quase três vezes maior que o da rede privada. No entanto, comparando a relação entre o número de matrículas nas escolas de cada rede e o número dos que prestaram o exame, verificou-se que $61 \%$ dos alunos da rede privada realizaram 0 exame, enquanto na rede pública somente $35 \%$ o fizeram.

Considerando a relação entre o número de matrículas na $3^{\text {a }}$ série do ensino fundamental e o número de escolas em cada uma das redes, observamos que, em média, estão matriculados na $3^{\text {a }}$ série nas escolas privadas, 66 alunos, enquanto nas públicas, são 206 matrículas. Essa constatação parece indicar aspectos que diferenciam as duas redes, como por exemplo, o número de alunos em turma, o que poderia ajudar a explicar a diferença de desempenho verificada entre elas.

A partir desse recorte, buscamos as vinte escolas com as melhores médias totais (redação e prova objetiva) com correção de participação dentre aquelas que participaram no ENEM em 2005, 2006 e 2007 (INEP, 2007, 2008a, 2008b). Em seguida, verificamos que apenas onze delas estavam presentes nos três anos. Dentre elas retiramos as que não tinham ensino fundamental completo - critério semelhante ao utilizado na seleção das escolas da rede pública municipal como se verá adiante - por considerarmos que elas não seriam as mais indicadas para estudarmos a construção de habitus escolares, que supõem um desenvolvimento processual e uma ação institucional mais abrangente e prolongada no tempo (PAES DE CARVALHO, 2004).

Em seguida, optamos por também excluir as escolas técnicas, considerando a especificidade de seu perfil organizacional, que agregaria novos fatores à análise da seleção de escolas que incluiria as escolas públicas municipais (que não têm esta característica) para uma interlocução com a literatura na perspectiva relacional de Bourdieu que a pesquisa pretende perseguir. Finalmente, retiramos do universo potencial para seleção a partir do ENEM, as escolas públicas (que foram objeto de 
um processo específico de seleção descrito a seguir) e as escolas que já haviam participado de nosso survey anterior ${ }^{8}$, na perspectiva de ampliar e diversificar 0 espectro das escolas pesquisadas.

Desta forma selecionamos seis escolas privadas, incluindo neste conjunto uma escola com características marcadamente empresariais ${ }^{9}$, que apresentara ótimos resultados em 2005 e 2006, mas que, pela falta de alguns dados exigidos pelo INEP, não fora incluida na listagem do ENEM 2007 (INEP, 2008b).

Na etapa final da seleção, classificamos as seis escolas selecionadas - em quatro das quais pretendemos realizar a pesquisa - em dois grupos, definindo $1^{\text {a }}$ e $2^{\text {a }}$ opção de escolha, numa estratégia preventiva de ocorrência de algum impedimento ou não autorização para a realização da pesquisa em alguma delas. Os critérios utilizados para definir cada opção foram as médias (em ordem decrescente) no ENEM nos três anos, 0 número de participantes (em ordem decrescente) e a localização, de forma a abranger diferentes bairros da cidade do Rio de Janeiro, como apresenta o Quadro 1 a seguir.

\begin{tabular}{|l|c|c|c|c|c|c|c|}
\hline Escolas & \multicolumn{3}{|c|}{$\begin{array}{c}\text { Média Total (redação e prova } \\
\text { objetiva) com correção } \\
\text { de participação }\end{array}$} & \multicolumn{2}{c|}{$\begin{array}{l}\text { Número de Alunos Concluintes } \\
\text { do Ensino Médio Participantes }\end{array}$} & Bairro \\
\hline & 2005 & 2006 & 2007 & 2005 & 2006 & 2007 & \\
\hline 1 & 76,67 & 67,69 & 76,82 & 66 & 74 & 88 & Centro \\
\hline 2 & 80,33 & 69,02 & --- & 153 & 175 & --- & Tijuca \\
\hline 3 & 78,24 & 71,71 & 79,20 & 133 & 160 & 176 & Barra da Tijuca \\
\hline 4 & 81,6 & 72,31 & 82,04 & 157 & 168 & 197 & Leblon \\
\hline 5 & 75,63 & 67,4 & 78,28 & 78 & 108 & 94 & Cosme Velho \\
\hline 6 & 74,17 & 67,28 & 76,76 & 71 & 53 & 67 & Gávea \\
\hline 7 & 75,68 & 66,24 & 75,57 & 68 & 73 & 81 & Gávea \\
\hline & \multicolumn{7}{|c|}{ Escolas selecionadas em 1 ${ }^{\text {a }}$ opção. } \\
\hline
\end{tabular}

Quadro1: Escolas privadas selecionadas para pesquisa.

Fonte: INEP (2008b).

\section{Escolha de Escolas da Rede Pública Municipal: ensaio e crítica dos passos iniciais}

Como a pesquisa pretendia estudar alunos, pais e professores do $9^{\circ}$ ano de quatro das melhores escolas públicas municipais, procuramos reunir os dados públicos ofici-

8 A maioria delas se enquadrava nos critérios utilizados nesta nova seleção, embora não tivessem sido escolhidas com tais procedimentos, já que à época (2001) os dados do ENEM por escola não estavam ainda disponibilizados publicamente.

9 A escola 2, presente em todos os ranqueamentos veiculados pela mídia a partir dos resultados do ENEM e dos vestibulares para as carreiras e instituições de ensino superior de maior prestígio na cidade. 
ais disponiveis sobre as escolas, em especial as informações e indicadores educacionais presentes no IDEB 2005 e 2007 (INEP, 2009) ${ }^{10}$ e no Censo Escolar 2005 (INEP, 2006).

Segundo a Secretaria Municipal de Educação do Rio de Janeiro (SME-RJ, a rede municipal é composta por 1.062 escolas, sendo que destas, 131 funcionam em horário integral, 252 são creches próprias do municipio, e 161 são unidades de educação infantil conveniadas. A rede municipal conta com 36.039 professores, 727.776 alunos e 12.137 funcionários de apoio administrativo (RIO DE JANEIRO, [200-b]). A Tabela 5 apresenta a distribuição das matrículas nas diferentes modalidades de ensino.

Tabela 5: Alunos Matriculados por Modalidade de Ensino na Rede Pública do Município do Rio de Janeiro.

\begin{tabular}{l|l}
\hline Modalidade & Alunos matriculados em 2008 \\
\hline Educação Infantil (creches e pré-escolas) & 115.736 \\
\hline $1^{\circ}$ Segmento do ensino fundamental (1 ${ }^{\circ}$ Ciclo de Formação e & \\
$2^{\circ}$ Ciclo de Formação - periodo inicial e intermediário) & 459.707 \\
\hline $2^{\circ}$ segmento do ensino fundamental (2॰ Ciclo de Formação - & \\
periodo final e $3^{\circ}$ Ciclo de Formação) & 268.069 \\
\hline Educação Especial & 6.179 \\
\hline Programa de Educação de Jovens e Adultos (EJA) & 32.954 \\
\hline
\end{tabular}

Fonte: Rio de Janeiro ([200-b])

A estrutura da Secretaria Municipal de Educação do Rio de Janeiro possui um nivel central e dez Coordenadorias Regionais de Educação (CRE), que cobrem as diferentes regiões do município como mostra o mapa a seguir:

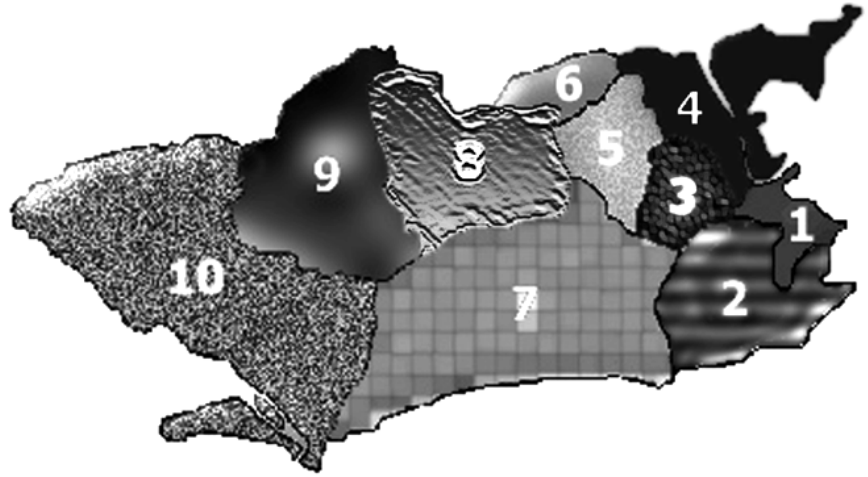

Mapa 1: Coordenadorias Regionais de Educação do Município do Rio de Janeiro. Fonte: Rio de Janeiro (2003).

100 Índice de Desenvolvimento da Educação Básica (IDEB) é um indicador calculado a partir dos dados sobre aprovação escolar (indicador de rendimento), obtidos no Censo Escolar, e das médias de desempenho nas avaliações do INEP, o SAEB (para as unidades da federação e para o país) e a Prova Brasil (para os municípios). 
Cada Coordenadoria engloba um conjunto de bairros, que possuem características sociodemográficas bastante distintas, bem como detém uma oferta também diferenciada de serviços públicos (RIO DE JANEIRO, 2003). Além disso, como mostram diversos estudos, o IDH entre bairros, mesmo numa única região ou CRE ${ }^{11}$, pode variar consideravelmente, expressando as caracteristicas peculiares da cidade, que repercutem também na educação (ALVES; FRANCO; RIBEIRO, 2008).

0 Gráfico 4 mostra o nível sócioeconômico médio (NSE) - identificado a partir dos dados da Prova Brasil 2005 - das escolas segundo a CRE tanto para os alunos da $4^{\text {a }}$ série quanto da $8^{\mathrm{a}}$ série do Ensino Fundamental.

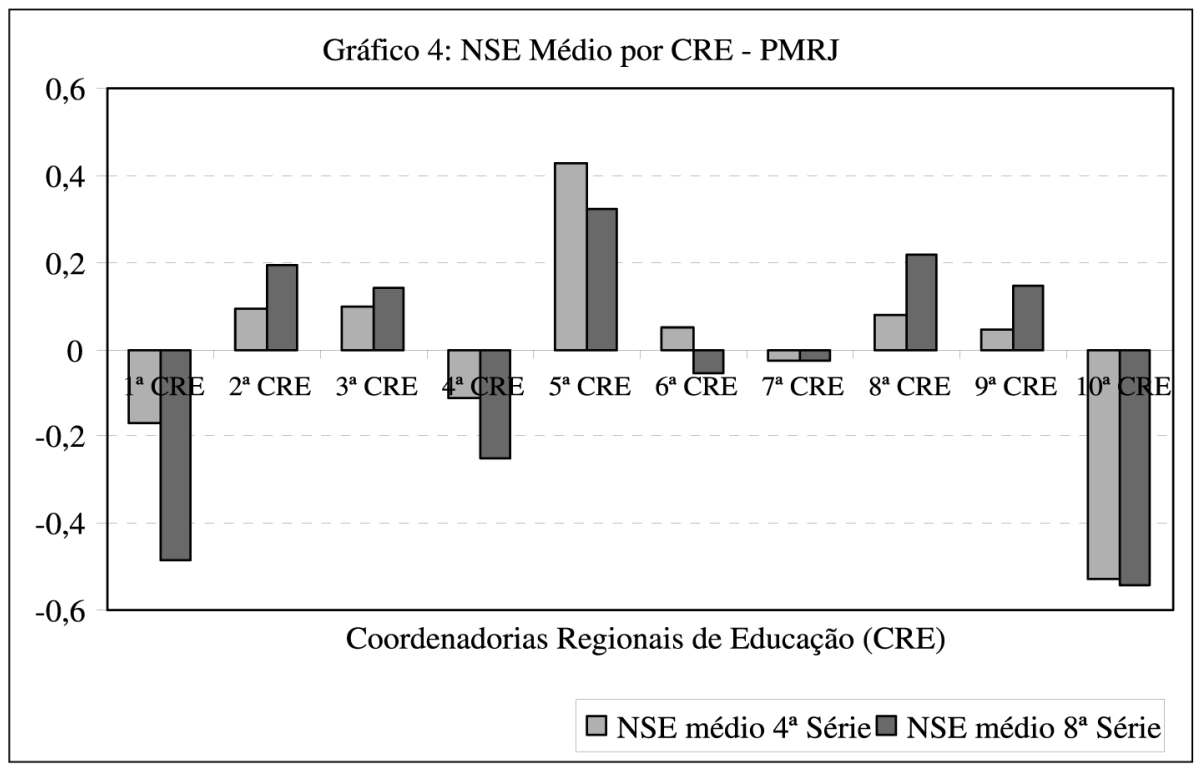

Gráfico 4: NSE Médio por CRE da Prefeitura Municipal do Rio de Janeiro. Fonte: INEP (2006).

0 gráfico 4 mostra tanto variações entre as $C R E$, como também dentro de uma mesma CRE. Observa-se que entre as CRE há uma grande variação da média de NSE: enquanto a $5^{\text {a }}$ CRE possui escolas com uma composição de alunado com NSE mais elevada, a 10 ${ }^{\text {a }}$ CRE apresenta um perfil de escolas com médias de NSE dos alunos mais baixas. Já dentro de cada uma das CRE são encontradas variações relevantes no NSE Médio por CRE relativo à $4^{\text {a }}$ Série e à $8^{\text {a }}$ Série - provavelmente em razão da seletividade ${ }^{12}$ frequentemente observada nas séries finais do ensino funda-

11 A relação de bairros que compõe cada CRE e encontra-se no ANEXO A, do presente texto.

12 Referimo-nos aqui ao fluxo decrescente de matrículas ao longo do ensino fundamental, que via de regra se articula ao rendimento escolar e ao nível sócio-econômico. 
mental como apontam diversos autores (SILVA; HASENBALG, 2002; ALVES; SOARES, 2003), entre vários outros), exceto no caso da $6^{\mathrm{a}} \mathrm{CRE}^{13}$.

0 primeiro passo foi tentar, também neste caso, construir uma espécie de "mapa" da rede escolar municipal e entender como estava organizada a rede na qual as escolas que pretendiamos pesquisar estão inseridas ${ }^{14}$, uma vez que nossa primeira incursão exploratória nos dados mostrou uma configuração bastante diversificada da oferta educacional de ensino fundamental nos 922 estabelecimentos que oferecem este nível de ensino na cidade $^{15}$, como mostra a Tabela 6:

Tabela 6: Escolas Municipais do Rio de Janeiro segundo a estrutura do ensino fundamental.

\begin{tabular}{l|c|c}
\hline Escolas & $\mathrm{N}$ & $\%$ \\
\hline $1^{\circ}$ ciclo $+4^{\circ}$ e $5^{\circ}$ anos (antigo primeiro segmento) & 542 & 58,8 \\
\hline Ensino fundamental completo com oito ou nove anos & 174 & 18,9 \\
\hline $6^{\circ}$ ano $+3^{\circ}$ ciclo (antigo segundo segmento) & 146 & 15,8 \\
\hline $5^{\circ}$ e $6^{\circ}$ Anos e o $3^{\circ}$ ciclo & 17 & 1,8 \\
\hline $2^{\circ}$ e $3^{\circ}$ ciclos & 12 & 1,3 \\
\hline Outras configurações $^{16}$ & 38 & 3,6 \\
\hline Total & 922 & 100,0 \\
\hline
\end{tabular}

Fonte: INEP (2006, 2007, 2008b)

Como todas as escolas de prestígio que vimos pesquisando nos últimos anos têm ensino fundamental completo, esse foi mais uma vez o primeiro critério de seleção ou recorte, restringindo assim o universo para a escolha às 174 escolas da rede municipal da cidade que possuíam este nível de ensino completo no momento da seleção.

Prosseguindo a construção do "mapa" do campo a ser investigado, buscamos os dados do IDEB 2005 e 2007 para 4ª e 8a séries, bem como as notas médias padronizadas da Prova Brasil nestas duas edições. As informações sobre a rede municipal do Brasil e da cidade do Rio de Janeiro são apresentadas na tabela a seguir.

13 Esta Coordenadoria fica na Zona Suburbana da cidade e inclui os bairros de Guadalupe, Anchieta, Pavuna, Ricardo de Albuquerque, Acari, Irajá e Barros Filho.

14 Para descrever a estrutura da rede, utilizamos as taxas de aprovação em cada série do ensino fundamental do IDEB 2005 e 2007 (INEP, 2009), e o número de matrículas em cada série do Censo 2005 (INEP, 2005)

15 Dos 1.062 estabelecimentos escolares, 140 oferecem apenas educação infantil.

160 quadro agrupou os subconjuntos mais numerosos de tipos de estrutura, mas foram também encontradas "outras configurações" em número bem inferior, tais como: seis escolas com o $3^{\circ}$ ano (do $1^{\circ}$ ciclo) e com o $2^{\circ}$ e $3^{\circ}$ ciclos; três com $3^{\circ}$ e $4^{\circ}$ anos, $6^{\circ}$ ano e $3^{\circ}$ Ciclo; três com $1^{\circ}$ e $2^{\circ}$ ciclos e o $7^{\circ}$ ano; duas com $1^{\circ}$ e $2^{\circ}$ ciclo; duas com $1^{\circ}$ ciclo e o $4^{\circ}$ ano; duas com $1^{\circ}$ ciclo, $4^{\circ}$ ano, $6^{\circ}$ ano e $3^{\circ}$ ciclo; duas com $2^{\circ}$ e $3^{\circ}$ ano e o $2^{\circ}$ e o $3^{\circ}$ ciclo. Todas as demais configurações tinham no máximo uma escola. 
Tabela 7: Rede municipal do Brasil e da cidade do Rio de Janeiro.

\begin{tabular}{l|c|c|c|c|c|c}
\hline Série & \multicolumn{2}{|c|}{ Indicador de Rendimento } & \multicolumn{2}{|c|}{ Nota Média Padronizada } & \multicolumn{2}{c}{ IDEB } \\
\hline & $\mathbf{2 0 0 5}$ & $\mathbf{2 0 0 7}$ & $\mathbf{2 0 0 5}$ & $\mathbf{2 0 0 7}$ & $\mathbf{2 0 0 5}$ & $\mathbf{2 0 0 7}$ \\
\hline & $\mathrm{BR}$ & $\mathrm{RJ}$ & $\mathrm{BR}$ & $\mathrm{RJ}$ & $\mathrm{BR}$ & $\mathrm{RJ}$ \\
$\mathrm{BR}$ & $\mathrm{R}$ & $\mathrm{BR}$ & $\mathrm{R}$ & $\mathrm{BR}$ & $\mathrm{RJ}$ & \\
\hline $4^{\text {a }}$ série & 0,8 & 0,87 & 0,84 & 0,93 & 4,3 & 4,91 \\
4,73 & 4,86 & 3,4 & 4,2 & 4,0 & 4,5 & \\
\hline $8^{\mathrm{a}}$ série & 0,74 & 0,79 & 0,78 & 0,92 & 4,18 & 4,71 \\
4,4 & 4,62 & 3,1 & 3,7 & 3,4 & 4,3 & \\
\hline
\end{tabular}

Fonte: INEP (2009)

Comparando com os dados do conjunto das redes municipais do Brasil, os resultados da cidade do Rio de Janeiro, para os indicadores selecionados em 2005 e 2007, são superiores, embora tenha ocorrido um decréscimo de 2005 para 2007 na nota média padronizada nas duas séries.

Inicialmente consideramos que as melhores escolas municipais com ensino fundamental completo seriam aquelas em que houve um maior crescimento na aprendizagem dos alunos entre 2005 e 2007 e, para isso, verificamos a diferença na nota média padronizada na $4^{\text {a }}$ e $8^{a}$ séries, apresentada a seguir.

Tabela 8: Diferença na nota média padronizada das escolas municipais da cidade do Rio de Janeiro com ensino fundamental completo.

\begin{tabular}{l|c|c|l}
\hline Série & \multicolumn{2}{|l|}{$\begin{array}{l}\text { Diferença na nota } \\
\text { média padronizada }\end{array}$} & $\begin{array}{l}\text { Percentual de escolas com } \\
\text { diferença positiva (maior que zero) }\end{array}$ \\
\hline & Mínimo & Máximo & \\
\hline $4^{\mathrm{a}}$ & $-1,56$ & 1,27 & $40 \%$ \\
\hline $8^{\mathrm{a}}$ & $-1,2$ & 1,1 & $25 \%$ \\
\hline
\end{tabular}

Fonte: INEP (2009).

Para selecionarmos as melhores escolas, impusemos ainda a condição de que a diferença na nota média padronizada nas duas séries deveria ser igual ou maior a 0,5 . Apenas três escolas se enquadravam nesse critério de seleção tão estrito, levando-nos a reduzir a diferença na média padronizada na 4 a série para apenas maior que zero, ou seja, uma diferença positiva, o que elevou o número de escolas que atendiam ao critério para dez. Entretanto, quando analisamos as notas padronizadas de cada uma delas percebemos que, se considerássemos as duas séries em 2005, suas médias (ainda que contassem com diferenças positivas) eram inferiores à média da rede municipal naquele ano. 
Considerando os resultados da Prova Brasil de 2007, observamos que na maioria das escolas, as notas na $4^{a}$ e $8^{a}$ séries, apesar do crescimento, continuavam menores que as da média da rede municipal. Tais resultados nos levaram a rever a pertinência da utilização do critério de "melhoria na nota média padronizada", uma vez que as escolas municipais que tinham obtido os melhores resultados na Prova Brasil, em 2005 e em 2007, não ficavam entre as selecionadas dessa forma. Ou seja, não necessariamente as melhores tinham também logrado melhorar suas notas médias entre as duas edições da Prova Brasil. Dessa forma, abandonamos o critério da diferença das notas médias padronizadas entre 2005 e 2007 para $4^{\text {a }}$ e $8^{\text {a }}$ séries e buscamos novos critérios a partir de uma nova exploração da distribuição das diferentes configurações das escolas municipais que ofereciam um ou mais anos ou ciclos do ensino fundamental segundo as diferentes Coordenadorias Regionais de Educação, nas quais a rede municipal se encontra organizada. Além disso, optamos por articular os dados do IDEB e da Prova Brasil 2005 e 2007 com os do Censo Escolar 2005, a fim de ter mais informações disponiveis ${ }^{17}$.

\section{Encontrando novos caminhos para a escolha de escolas da Rede Pública Municipal}

Considerando as 174 escolas municipais com ensino fundamental completo, vimos que nem todas as escolas foram avaliadas nas duas séries, nos dois anos; com isso, nosso universo foi reduzido para 155 escolas. Selecionamos, então, aquelas em que a nota média padronizada na $4^{\mathrm{a}}$ e na $8^{\mathrm{a}}$ séries fosse superior à média da rede municipal da cidade do Rio de Janeiro tanto em 2005, como em 2007, estabelecendo assim o conjunto de estabelecimentos de ensino da rede municipal com melhores resultados na Prova Brasil em 2005 e 2007. A seguir, apresentamos um quadro geral das escolas municipais com ensino fundamental completo, considerando as médias da rede ${ }^{18}$ em relação às notas médias padronizadas na 4a e 8 $8^{\text {a }}$ séries em 2005 e 2007.

\begin{tabular}{|l|l|l|l|c|}
\hline \multicolumn{2}{|l|}{ Número de escolas segundo a nota média padronizada - 2005 e 2007} \\
\hline & \multicolumn{2}{|l|}{$\mathbf{8}$ S } & Total \\
\cline { 3 - 5 } \multicolumn{2}{|l|}{} & Abaixo da média & Acima da média & \\
\hline 4aS & Abaixo da média & 90 & 21 & 111 \\
\hline & Acima da média & 13 & 31 & 44 \\
\hline Total & & 103 & 52 & 155 \\
\hline
\end{tabular}

Quadro 2: Escolas com ensino fundamental completo pela média da rede municipal na nota média padronizada na $4^{\mathrm{a}}$ e $8^{\mathrm{a}}$ Séries em 2005 e 2007.

Fontes: INEP (2006, 2009).

17 Através dos microdados do Censo Escolar 2005 pudemos obter o nível socioeconômico médio por escola (NSE) com base nas informações dos alunos de $8^{\text {a }}$ Série.

18 Em relação à nota média padronizada, a média da rede municipal da cidade do Rio de Janeiro para $4^{\mathrm{a}}$ série foi 4,91, em 2005, e 4,86, em 2007. Para 8a série foi 4,71, em 2005, e 4,62, em 2007. 
Encontramos 31 escolas com médias superiores à média da rede municipal na nota média padronizada na $4^{\mathrm{a}}$ e $8^{\mathrm{a}}$ séries, tanto em 2005, como em 2007, distribuídas entre oito das dez Coordenadorias Regionais de Educação (CRE), como apresentamos a seguir no Tabela 10.

\begin{tabular}{|l|c|c|c|c|c|c|c|c|c|c|c|}
\hline CRE & $1^{\mathrm{a}}$ & $\mathbf{2}^{\mathrm{a}}$ & $\mathbf{3}^{\mathrm{a}}$ & $4^{\mathrm{a}}$ & $5^{\mathrm{a}}$ & $\mathbf{6}^{\mathrm{a}}$ & $\mathbf{7}^{\mathrm{a}}$ & $\mathbf{8}^{\mathrm{a}}$ & $\mathbf{9}^{\mathrm{a}}$ & $\mathbf{1 0}^{\mathrm{a}}$ & Total \\
\hline №. de escolas & 1 & 7 & 7 & 9 & 4 & 0 & 1 & 1 & 1 & 0 & 31 \\
\hline
\end{tabular}

Quadro 3: Escolas com ensino fundamental completo e nota média padronizada na $4^{\mathrm{a}}$ e $8^{\mathrm{a}}$ séries superior à média da rede municipal por CRE.

Fonte: INEP $(2006,2009)$.

Considerando esta distribuição das escolas entre oito CRE, decidimos que escoIheriamos, preferencialmente, escolas de diferentes CRE, levando em consideração a heterogeneidade da distribuição espacial dos recursos econômicos, sociais e culturais na cidade, como já assinalado anteriormente. Assim, seria possivel pesquisar as melhores escolas municipais em diferentes regiões da cidade do Rio de Janeiro.

Ainda assim, era preciso estabelecer novos critérios para selecionar, quatro escolas dentre as 31 encontradas. 0 primeiro critério para o novo recorte foi o número total de matrículas no ensino fundamental do $1^{\circ}$ ao $9^{\circ}$ ano em 2008 - que fornece uma dimensão ou porte da escola. 0 segundo critério foi o Nivel Sócioeconômico (NSE) médio da $8^{\text {a }}$ Série aferido em 2005. Para cada caso, analisamos a distribuição geral entre as 155 escolas que ofereciam ensino fundamental completo e para as quais tínhamos dados da Prova Brasil em 2005 e 2007, criando então quatro faixas com a intenção de escolher quatro escolas que tivessem o maior número de matrículas, sendo uma em cada faixa de NSE médio.

Em relação ao total de matrículas, as faixas ficaram assim distribuídas: faixa 1 com até 729 matrículas; faixa 2 com 730 a 845; faixa 3 com 846 a 1081; e faixa 4 com mais de 1082 matrículas. 0 mesmo procedimento foi realizado em relação à definição das quatro faixas de NSE. Aplicados os dois critérios simultaneamente, verificamos que nenhuma escola na faixa 4 do NSE tinha mais de 1082 matrículas, o que nos levou a rever as faixas predefinidas e agregar as escolas das faixas 3 e 4 de número de matrículas, ou seja, com mais de 846 alunos. Encontramos então 15 escolas distribuídas em cinco CRE.

Antes de realizarmos a seleção final das escolas procuramos verificar a estrutura de ensino em cada uma delas em 2008, no sentido de confirmar se continuavam oferecendo ensino fundamental completo em 2008 com base nas informações disponibilizadas na página da Secretaria Municipal de Educação na Internet. Apenas uma escola (a única da 9a CRE) foi excluída, pois em 2008 oferecera apenas o $2^{\circ}$ e $3^{\circ}$ ciclos. 
Apresentamos no Quadro 4 a seguir, a distribuição das escolas municipais que integraram a seleção final a partir dos critérios e procedimentos acima descritos, cuja numeração reflete sua posição no ranking geral de acordo com os resultados da Prova Brasil.

\begin{tabular}{|l|l|l|l|l|l|}
\hline CRE & Escolas & \multicolumn{5}{|l|}{ Faixas de NSE Médio - 8a. Série 2005 } & \\
\hline & & 1 & 2 & 3 & 4 \\
\hline 2 & 1 & & & & \\
\hline & 2 & & & & \\
\hline 3 & 5 & & & & \\
\hline & 10 & & & & \\
\hline & 11 & & & & \\
\hline & 12 & & & & \\
\hline 4 & 3 & & & & \\
\hline & 4 & & & & \\
\hline & 6 & & & & \\
\hline & 7 & & & & \\
\hline & 8 & & & & \\
\hline & 9 & & & & \\
\hline 5 & 13 & & & & \\
\hline & 14 & & & & \\
\hline
\end{tabular}

Quadro 4: Escolas com mais de 846 matrículas de $1^{\circ}$ ao $9^{\circ}$ ano, por CRE e por faixas de NSE médio da 8a série, em 2005.

Fontes: INEP (2006, 2009).

Em cada faixa de NSE médio, quando foi possível ${ }^{19}$, escolhemos duas escolas com o objetivo de ter uma segunda opção, caso na primeira encontrássemos alguma dificuldade ou impedimento para a realização da pesquisa. A seleção da primeira e da segunda opção foi realizada levando-se em consideração a localização das escolas em diferentes CRE, a maior nota média padronizada da $8^{a}$ série em 2007, e o maior número de matrículas no $9^{\circ}$ ano em 2008. 0 Quadro 5 apresenta as oito escolas selecionadas:

\begin{tabular}{|l|c|c|c|c|c|}
\hline Opção & CRE & Escolas & $\begin{array}{l}\text { Faixa de NSE médio } \\
-\mathbf{8}^{\text {a Série - 2005 }}\end{array}$ & $\begin{array}{l}\text { Nota média } \\
\text { padronizada - 8a Série - 2007 }\end{array}$ & $\begin{array}{c}\text { Matrículas no } \\
\mathbf{9}^{\mathbf{0}} \text { ano - 2008 }\end{array}$ \\
\hline $1^{\mathrm{a}}$ & 2 & 1 & 4 & 5,96 & 133 \\
\hline $2^{\mathrm{a}}$ & 3 & 12 & & 4,65 & 108 \\
\hline $1^{\mathrm{a}}$ & 5 & 13 & 3 & $5,06^{20}$ & 127 \\
\hline $2^{\mathrm{a}}$ & 2 & 2 & & 5,37 & 111 \\
\hline $1^{\mathrm{a}}$ & 3 & 11 & 2 & 5,07 & 86 \\
\hline $1^{\mathrm{a}}$ & 4 & 7 & 1 & 5,62 & 169 \\
\hline $2^{\mathrm{a}}$ & 3 & 10 & & 4,89 & 67 \\
\hline
\end{tabular}

Quadro 5: Escolas municipais selecionadas para pesquisa.

Fontes: INEP (2006, 2009) e Rio de Janeiro ([200-b]).

19 Apenas para uma faixa de NSE, a segunda, não foi possível escolher duas escolas.

20 Apesar da nota média padronizada da $1^{\mathrm{a}}$ opção ser inferior a da $2^{\mathrm{a}}$, consideramos primeiro, a localização da escola na $5^{\text {a }}$ CRE. 


\section{Considerações finais}

Este trabalho procurou detalhar os bastidores do processo de construção de um survey sobre processos organizacionais e pedagógicos que articulam os agentes escolares na produção do sucesso escolar, descrevendo os caminhos trilhados, que desafiaram, em muitos momentos, nossa imaginação e compromisso com o rigor metodológico. Nele enfatizamos o uso dos dados das avaliações de larga escala do INEP $(2006,2009)$ e da Secretaria Municipal de Educação do Rio de Janeiro ([200a], [200-b]), usufruindo - em benefício do conhecimento e da busca da qualidade da educação - da riqueza destas bases de dados já construídas, na perspectiva de valorizar o investimento público realizado em sua construção e disponibilidade também na investigação acadêmica.

Acreditamos ter feito justiça à discussão metodológica e à trajetória de pesquisa que vimos desenvolvendo há vários anos na perspectiva de realizar a seleção do campo de estudo, sem perder de vista a pertinência conceitual das escolhas e critérios definidos (VAN ZANTEN, 2004), conforme nossos interesses previamente delineados de investigação e o escopo teórico da obra de Bourdieu que nos tem inspirado. Ao lado disso, previmos igualmente no desenho da amostra de escolas a serem investigadas alternativas para negociar no marco da interação com os agentes envolvidos - como sugere a autora citada - na medida em que definimos mais de uma opção de escolha sem fugir aos critérios gerais.

Esperamos que o registro detalhado e fundamentado do processo de seleção de escolas não apenas forneça um horizonte de investigação rico e rigorosamente delimitado, como também possa inspirar outros pesquisadores em seus empreendimentos acadêmicos e contribuir para a discussão metodológica no campo da sociologia da educação. 


\section{Referências}

ALVES, M. T. G.; SOARES, J. F. As pesquisas sobre o efeito das escolas: contribuições metodológicas para a Sociologia da Educação. Revista Sociedade e Estado, Brasília, DF, v. 22, n. 2, p. 435-473, maio/ago. 2007.

ALVES, F.; FRANCO, C.; RIBEIRO, L. C. O. Segregação residencial e desigualdades escolar no Rio de Janeiro. In: RIBEIRO, L. C. 0. ; KAZTMAN, R. (Org.). A cidade contra a escola? : segregação urbana e desigualdades educacionais em grandes cidades da América Latina. Rio de Janeiro: Letra Capital: FAPERJ; Montevidéu, Uruguai: IPPES, 2008.

BOURDIEU, P. Razões práticas: sobre a teoria da ação. Campinas: Papirus, 1997.

BRANDÃO, Z.; MANDELERT, D.; DE PAULA, L. A circularidade virtuosa: investigação sobre duas escolas no Rio de Janeiro. Cadernos de Pesquisa, São Paulo, v. 35, n. 126, p. 747-758, set./dez. 2005.

FERNANDES, S. Inscrições no Enem aumentam 2.170\%. Prima Página, Brasília, DF, 30 jul. 2008. Disponível em: <http://www.pnud.org.br/educacao/reportagens/ index.php?id01=3003ctlay=ecu>. Acesso em: 21 mar. 2011.

INEP. Censo escolar 2005. Brasilia, DF, 2006. <http://www.inep.gov.br/download/ censo/2005/resultados_censo2005.pdf>. Acesso em: 21 mar. 2011.

Enem: relatório pedagógico 2005. Brasilia, DF, 2007. Disponível em: <http://www.inep.gov.br/download/enem/relatorio/enem_2005.pdf>. Acesso em: 23 nov. 2008.

Enem: relatório pedagógico 2006. Brasília, DF, 2008a. Disponível em:<http://www.inep.gov.br/download/Enem/Relatorio/ENEM_2006.pdf>. Acesso em: 23 nov. 2008.

Enem: relatório pedagógico 2007. Brasília, DF, 2008b. Disponível em: <http://www.inep.gov.br/download/Enem/Relatorio/ENEM_2007.pdf>. Acesso em: 23 nov. 2008.

Médias do ENEM 2007, por escola e município. Brasília, DF, 2008c. Disponível em: <http://mediasenem.inep.gov.br/resultado,php>. Acesso em: 23 nov. 2008.

Estatísticas do IDEB. Brasília, DF, 2009. Disponível em: <http:// portalideb.inep.gov.br>. Acesso em: 21 mar. 2011. 
LEVIN, J. Estatística aplicada a ciências humanas. 2. ed. São Paulo: Harbra, 1987.

MAFRA, L. A. A sociologia dos estabelecimentos escolares: passado e presente de um campo de pesquisa em re-construção. In: ZAGO, N. et al. Itinerários de pesquisa: perspectivas qualitativas em sociologia da educação. Rio de Janeiro: DPEA, 2003.

MANDELERT, D. Pais na gestão da escola: mudam as relações?: uma análise sociológica de uma instituição judaica. 2005. Dissertação (Mestrado em Educação) - Pontifícia Universidade Católica, Rio de Janeiro, 2005.

MARTINS, H. H. T. S. Metodologia qualitativa de pesquisa. Revista Educação e Pesquisa, São Paulo, v. 30, n. 2, p. 289-300, maio/ago. 2004.

PAES DE CARVALHO, C. Entre as promessas da escola e os desafios da reprodução social: famílias de camadas médias do ensino fundamental à Universidade. 2004. Tese (Doutorado em Educação) - Departamento de Educação, PUC-Rio, 2004.

RIO DE JANEIRO (RJ). Secretaria Municipal de Urbanismo. Instituto Pereira Passos. Rio de Janeiro, 2003. (Coleção Estudos da Cidade).

RIO DE JANEIRO (RJ). Secretaria Municipal de Educação. Educação: estrutura. Rio de Janeiro, [200-a]. Disponivel em: <http://www.rio.rj.gov.br/sme/>. Acesso em: 5 set. 2008.

Educação: números. Rio de Janeiro, [200-b]. Disponivel em: <http:// www.rio.rj.gov.br/sme/numeros.htm>. Acesso em: 1 dez. 2008.

SILVA, N. V.; HASEMBALG, C. Recursos familiares e transições educacionais. Cadernos de Saúde Pública, Rio de Janeiro, n. 18, p. 67-76, 2002. Suplemento.

SOARES, J. F.; ALVES, M. T. G. Desigualdades raciais no sistema brasileiro de educação básica. Educação e Pesquisa, São Paulo, v. 29, n. 1, p. 147-165, jan./jun. 2003.

VAN ZANTEN, A. Comprender y hacerce comprender: como reforzar la legitimidad interna y externa de los estudios cualitativos. Revista Educação e Pesquisa, São Paulo: v. 30, n. 2, p. 301-313, maio/ago. 2004.

Recebido em: 09/02/2010

Aceito para Publicação em: 24/10/2010 


\section{ANEXO A: Coordenadorias Regionais de Educação do Município do Rio de Janeiro.}

\begin{tabular}{|c|c|c|}
\hline $\begin{array}{l}\text { Coordenadoria } \\
\text { Regional de Educação } \\
\text { - CRE }\end{array}$ & Localização & Bairros \\
\hline $1^{\text {a }} \mathrm{CRE}$ & Centro / Zona Norte & $\begin{array}{l}\text { Centro, Paquetá, Caju, Cidade Nova, } \\
\text { Catumbi, Rio Comprido, Lapa, Santa Teresa } \\
\text { São Cristóvão, Bairro de Fátima }\end{array}$ \\
\hline $2^{\mathrm{a}} \mathrm{CRE}$ & $\begin{array}{l}\text { Zona Sul / Centro / } \\
\text { Zona Norte }\end{array}$ & $\begin{array}{l}\text { Catete, Laranjeiras, Flamengo, Lagoa, } \\
\text { Botafogo, Leblon, Ipanema, Urca, Gávea, } \\
\text { São Conrado, Copacabana, Tijuca, } \\
\text { Alto da Boa Vista, Vila Isabel, Grajaú, Andaraí }\end{array}$ \\
\hline $3^{\mathrm{a}} \mathrm{CRE}$ & $\begin{array}{l}\text { Zona Norte/ } \\
\text { Zona Suburbana }\end{array}$ & $\begin{array}{l}\text { Higienópolis, Cachambi, Engenho de Dentro, } \\
\text { Engenho Novo, Méier, Piedade, Inhaúma, } \\
\text { Del Castilho, Engenho da Rainha, Rocha, Pilares }\end{array}$ \\
\hline $4^{\mathrm{a}} \mathrm{CRE}$ & Zona Suburbana & $\begin{array}{l}\text { Cordovil, Bonsucesso, Bancários, Penha, Olaria, } \\
\text { llha do Governador, Brás de Pina, Penha Circular, } \\
\text { Vigário Geral, Ramos }\end{array}$ \\
\hline $5^{\mathrm{a}} \mathrm{CRE}$ & Zona Suburbana & $\begin{array}{l}\text { Vila Kosmos, Irajá, Madureira, Marechal Hermes, } \\
\text { Rocha Miranda, Quintino Bocaiúva. }\end{array}$ \\
\hline $6^{\mathrm{a}} \mathrm{CRE}$ & Zona Suburbana & $\begin{array}{l}\text { Guadalupe, Anchieta, Pavuna, } \\
\text { Ricardo de Albuquerque, Acari, Irajá, Barros Filho }\end{array}$ \\
\hline $7^{\text {a }} \mathrm{CRE}$ & Zona Oeste & $\begin{array}{l}\text { Barra da Tijuca, Vargem Grande, Curicica, } \\
\text { Jacarepaguá, Taquara, Praça Seca, Vila Valqueire, } \\
\text { Tanque, Cidade de Deus, Anil, Rio das Pedras }\end{array}$ \\
\hline $8^{\mathrm{a}} \mathrm{CRE}$ & Zona Oeste & $\begin{array}{l}\text { Deodoro, Sulacap, Realengo, Padre Miguel, } \\
\text { Bangu, Senador Câmara, Jabour, Vila Aliança, } \\
\text { Vila Kenedy }\end{array}$ \\
\hline $9^{\mathrm{a}} \mathrm{CRE}$ & Zona Oeste & Inhoaiba, Campo Grande, Vasconcelos, Vila Nova, \\
\hline $10^{\mathrm{a}} \mathrm{CRE}$ & Zona Oeste & $\begin{array}{l}\text { Paciência, Santa Cruz, Sepetiba, Guaratiba, } \\
\text { Pedra de Guaratiba }\end{array}$ \\
\hline
\end{tabular}

Fonte: Rio de Janeiro ([200-a]). 